\title{
Nuevos ejemplos de esgrafiados en la arquitectura barroca valenciana
}

\author{
Albert Ferrer Orts \\ Universitat de València \\ albert.ferrer-orts@uv.es
}

Desde que diéramos a conocer el primer corpus de esgrafiados en la arquitectura barroca valenciana, estudio en el que se recogen las diversas investigaciones diseminadas sobre el particular hasta el momento (Ferrer, 2003a), conscientes como éramos de que a partir de entonces irían apareciendo otros desconocidos entonces, incorporamos a dicho acervo más ejemplos de esta decoración tan efectista que caracterizó sobremanera los interiores de numerosos edificios, particularmente religiosos. La desproporción entre las construcciones religiosas y civiles a que aludimos puede deberse tanto a los sucesivos cambios de estilo en la decoración que suelen experimentar las viviendas privadas, a su transformación radical o desaparición ren determinados contextos especulativos, como también a la mayor perdurabilidad de la ornamentación en arquitecturas dedicadas al culto católico. Sin embargo, también han ido desapareciendo o renovándose, cuando no disimulándose con gruesas capas de cal, numerosos esgrafiados afectados por los incendios durante la Guerra Civil.

Ya decíamos en aquel momento que la labor relativa a su censo quedaba lejos de estar concluida por la dificultad que encontramos tanto en la historiografía consultada -donde el uso del término adecuado para denominar esta técnica es infrecuente- (Ruiz Alonso, 2014a: 22-37, y 2014b: 208-229), como por la gran cantidad de arquitecturas que se reformaron profusamente o se construyeron de nueva planta en el período de su máxima difusión (ca. 1642-1710). Trabajo de campo que abarca los límites de la Comunidad Valenciana pero que no siempre coinciden con los que tuvo el reino de Valencia en época foral.

Es objeto, pues, de este texto seguir enriqueciendo el catálogo mencionado con los esgrafiados que en los últimos años hemos podido conocer, censar o estudiar y, con ello, seguir difundiendo y poniendo en valor una manera de entender la decoración arquitectónica que caracterizará durante más de media centuria a un elevado número de construcciones hasta que el impulso novator, el nacimiento de las Academias (de Santa Bárbara y de San Carlos, sucesivamente) y la llustración, en definitiva de otros gustos artísticos en sintonía con la sociedad surgida a consecuencia de la Guerra de Sucesión y canalizada a través de los intereses estéticos de una nueva dinastía, se conviertan progresivamente en su epílogo ${ }^{1}$.

En ese contexto, los edificios que incorporamos al catálogo, de carácter religioso en su mayor parte, están localizados en Alaquàs, Andilla, Beniatjar, Castellón de la Plana, Catí, l'Alcora y Pedreguer. Construcciones que se encuadran en el lapso cronológico aludido, al menos en su decoración, y que pasamos a relacionar.

Como sucede en la iglesia de Nuestra Señora de la Asunción de Alaquàs (Valencia), cuyos esgrafiados aparecen datados en $1680^{2}$, las obras de restauración de su palacio-castillo anexo -edificio de mediados del siglo XVI- llevadas a término hace unos años sacaron a la luz este tipo de motivos en algunas de sus dependencias, como la Sala de la Plata y el oratorio (Sena, 2016: 45). Esgrafiados que se nos antojan contemporáneos a los de la parroquia, pues denotan una misma mano e idéntica temática y cromatismo en sus frisos corridos de raigambre clasicista y en los lunetos de sus techumbres, mediante querubines entrelazados con pámpanos, hojas y racimos de uva o pájaros entre exuberantes hojas de acanto obedeciendo a la ley de la simetría [1]

El templo de Andilla (Valencia), dedicado a la Asunción y de trazado tardogótico, también presenta una buena muestra de trepa en su Capilla de la Comunión, aunque sospechamos que su ornamentación barroca pudo extender los esgrafiados, a los que iba asociada a menudo, al conjunto del edificio, junto a las yeserías, estucos y florones 


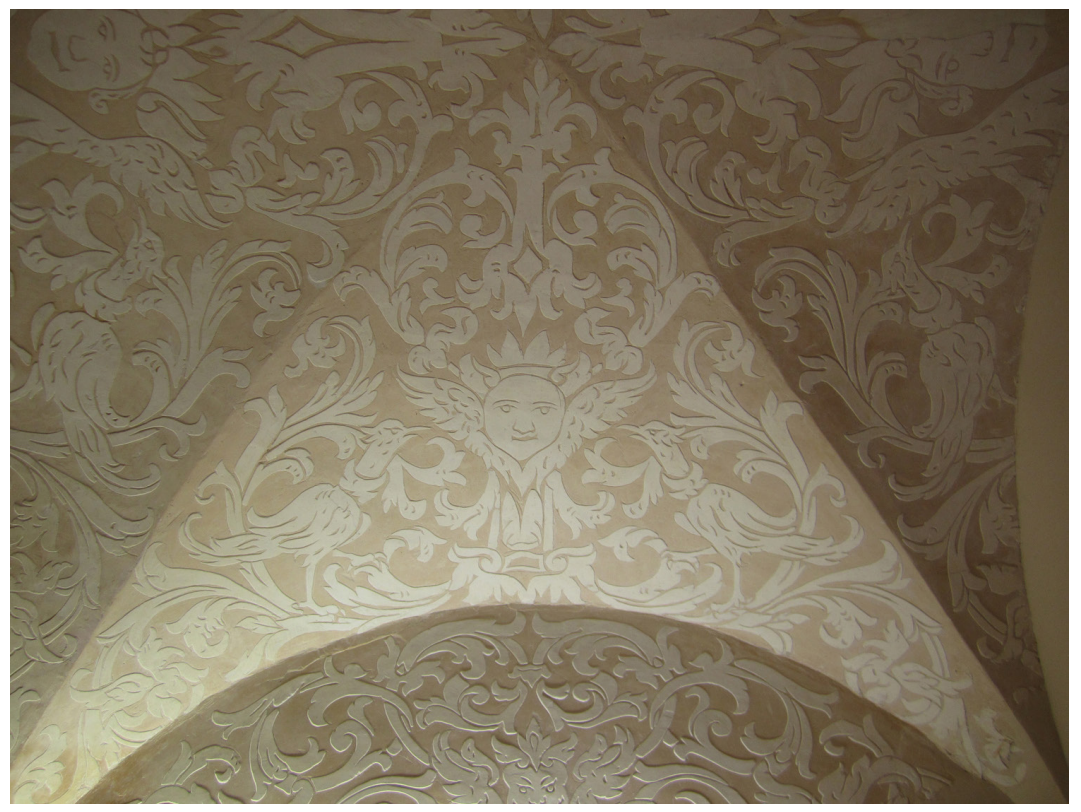

1. Esgrafiados del palacio-fortaleza, Alaquàs. Foto de TRJ

2. Esgrafiados de la iglesia parroquial de Nuestra Señora de la Asunción, Andilla. Foto de JLCM

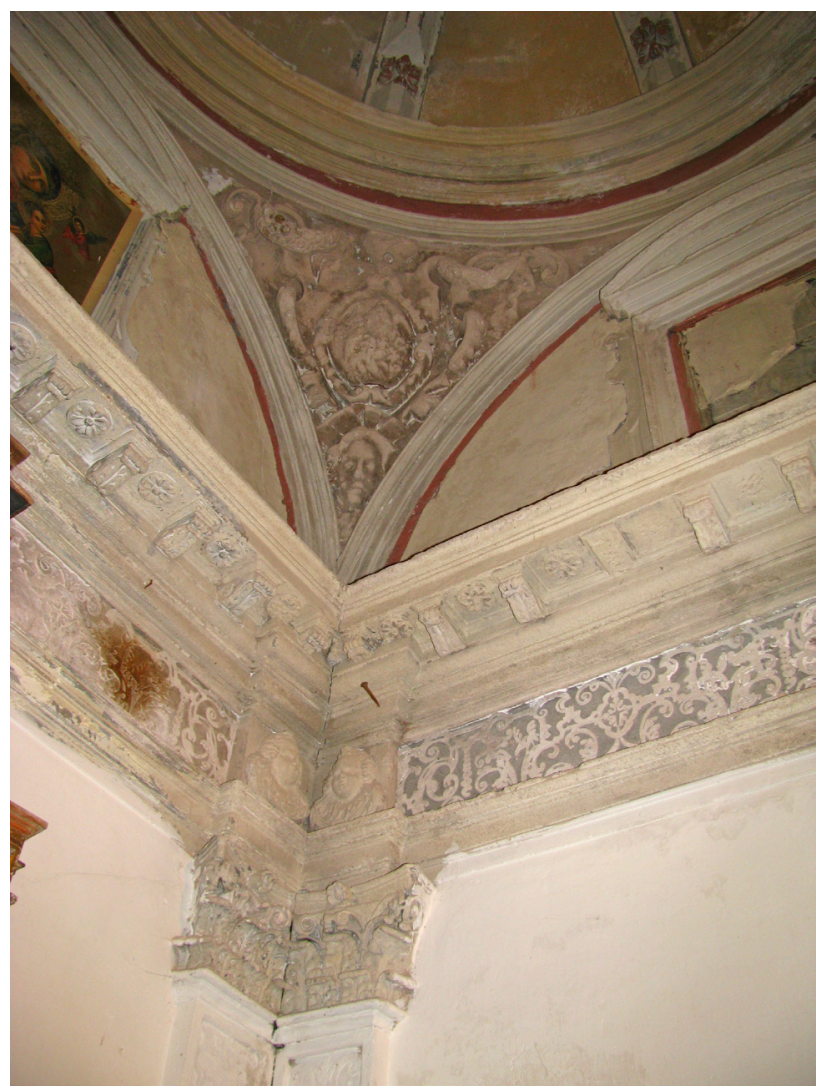

polícromos (hoy encalados en su mayoría) ${ }^{3}$. En dicha capilla todavía se observan estos motivos en su estado original, alternándose con otros pintados de blanco y gris según se trate de frisos, casetones o netos de las pilastras [2]. De hecho, observando con detenimiento dicho espacio, su arquitectura y ornamentación nos recuerdan sobremanera las de algunos espacios de la cartuja de Ara Christi, en el Puig, especialmente el trasaltar construido entre 1630-1639, en el que trabajaron los maestros de obras Martí d'Orinda, Pallarés y Jaume Rebull (Ferrer, 2004: t. I, 138). Dato que quizás pueda acercarnos a la fecha de realización de la capilla de Andilla y a la de su ulterior decoración.

La iglesia de Beniatjar (Valencia) ${ }^{4}$, concluida en 1689 por Pedro Revert según recoge una lápida en su fachada (García, 1972: 5), también fue exornada en su totalidad con esgrafiados. En su capilla destinada a baptisterio conserva esta decoración como motivo decorativo a través de gamas blancas sobre fondo marrón claro, quizás dos de los colores más socorridos, efectistas y populares asociados a la trepa en tierras valencianas, aunque las catas realizadas en sus paramentos desvelan que el marrón original era más oscuro [3]. Intervenidos recurrentemente (es decir, repintados la mayor de las veces), su perfilado pierde nitidez a medida que las sucesivas capas de pintura desvirtúan su primigenia frescura y originalidad. Sin embargo, lo que más llama 
la atención, como también sucede en otros edificios -por ejemplo el templo de Llombai- es el hecho de aparecer mediante diversas fajas verticales, repetidas o combinadas, con vegetación ascendente a base de emparrados, ángeles trepadores y aves picoteando racimos, separadas por otras exclusivamente de carácter vegetal (acanto), fruto quizás de cuestionables intervenciones posteriores a la Guerra Civil. En las embocaduras de alguna de sus capillas se observan estos motivos vegetales formando roleos y en su centro aparece una cara de tipo monstruoso, frecuente en los repertorios icónicos de tradición clásica.

Aunque ya desaparecida, la iglesia de San Juan Bautista en Castellón de la Plana, sede del gremio de sogueros y de oficiales mozos de San Cristóbal, fue ampliada en 1653, posteriormente reedificada en 1676 por el maestro de obras Jaume Esteller y reformada en 1686 por Josep Dols, se cubría con bóveda de cañón con lunetos y bóveda vaída en el presbiterio, esta última con esgrafiados (Gil Saura, 2004: 447448). Desgraciadamente, no tenemos constancia de información gráfica que pueda acercarnos a su naturaleza decorativa.

Cercana a Morella, la parroquial de Catí (Castellón) dedicada a la Asunción se edificó a principios del siglo XIV, aunque desde entonces fue sucesivamente ampliada hasta 1643, fecha en la que se construye la sacristía y el archivo, y 1667, año en el que se modifica la techumbre y su bóveda,

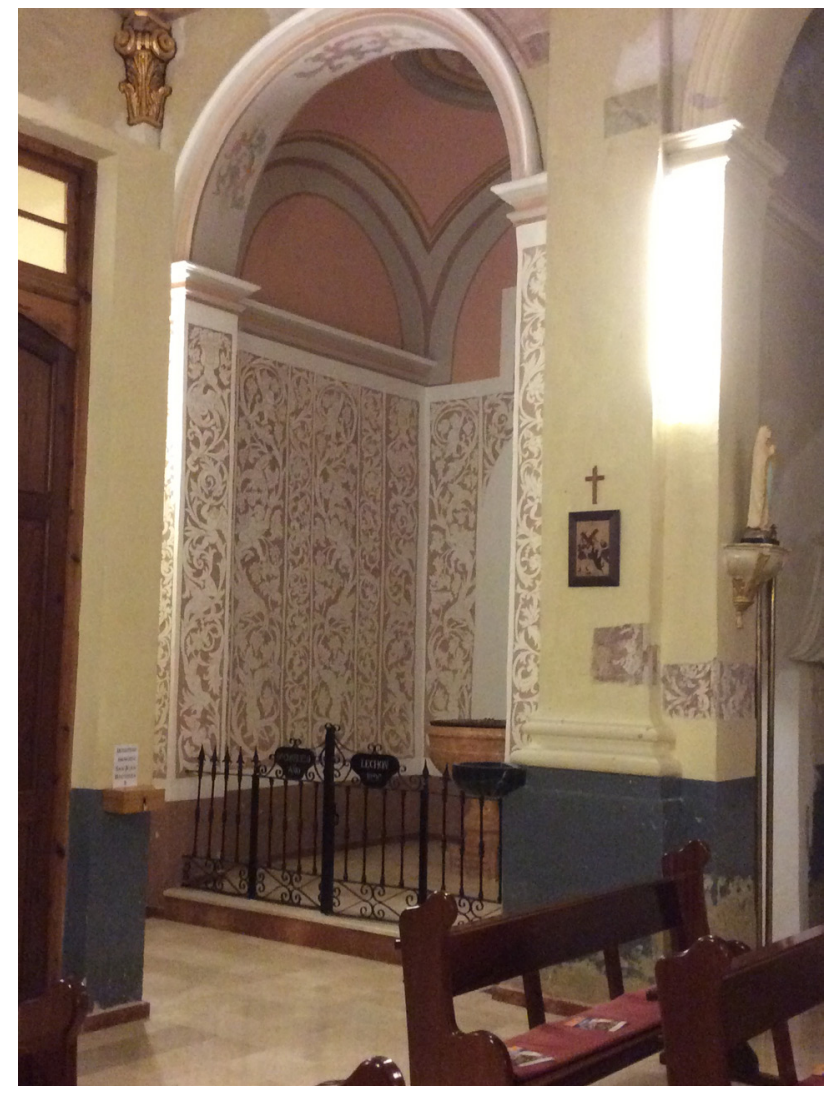

3. Esgrafiados de la iglesia parroquial de la Encarnación de Nuestra Señora, Beniatjar. Foto de JEAS
4. Esgrafiados de la iglesia parroquial de Nuestra Señora de la Asunción, l'Alcora. Foto de EC

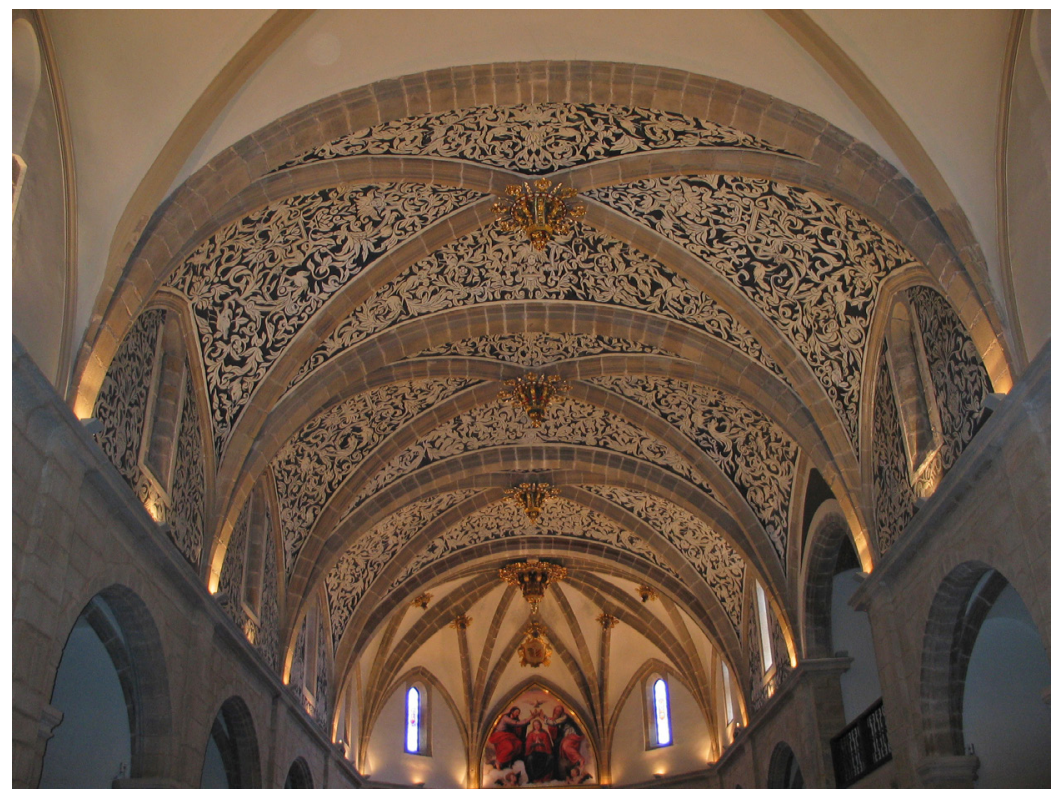


así como sus capillas, decorándose con esgrafiados entre 1666 y 1679 (Gil Saura, 2004: 287-289).

Otros de los ejemplos que hemos podido recabar se tratan del templo parroquial de Nuestra Señora de la Asunción, iglesia de origen medieval ampliada en la segunda mitad del siglo XVI, dotada de nuevo retablo mayor en 1680 y de capilla de comunión entre 1700-1705 (Gil Saura, 2004: 299-300), período en el que debió de esgrafiarse su bóveda de tradición gótica [4] a semejanza de la de Catí, y de la ermita de San Vicente Ferrer, en l'Alcora (Castellón), construida entre 1598 y 1609. Un edificio de planta de cruz latina rematado por una cúpula sin tambor sobre pechinas, exornada con yeserías en sus molduras y serafines a base de tonalidades blancas y azules, presumiblemente en las postrimerías del siglo XVII, como recoge Gil Saura (2004: 419) sin referirse a los esgrafiados.

La última muestra censada de este motivo decorativo característico del barroco valenciano se trata de la parro- quial de la Santa Cruz en Pedreguer (Alicante), cuya edificación primitiva data del siglo XV aunque su actual construcción de planta de cruz latina con cúpula sobre pechinas y capillas entre contrafuertes correspondería a finales de la siguiente centuria. Hacia finales del siglo XVII o principios del siglo XVIII fue íntegramente ornamentada con esgrafiados, desde sus pilastras de orden toscano y corintio hasta la bóveda de cañón con lunetos, a base de profusión de motivos vegetales formando simétricos roleos, aves, cánidos, putti y seres fantásticos, hoy recuperados gracias a las restauraciones llevadas a cabo en 1974 y $2003^{5}$. Uno de los mejores ejemplos de esgrafiado arquitectónico al sur del antiguo reino que conecta de alguna manera con otros edificios de la zona -casos de Dénia y Orihuela, según constatamos en su día (Ferrer: 2003a: 55-56)- pero que, sin embargo, parece que no tuvo el mismo predicamento en tierras alicantinas que en las actuales provincias de Valencia y Castellón.

\section{Notas}

1 Los trabajos que, sobre esgrafiados de esta naturaleza y cronología, hemos ido publicando desde nuestro estudio (y, por tanto, ampliando su catálogo) son: Ferrer (2003b: 47-54; 2005: 967-977; 2009: 173-178; 2010: 227-232; 2011: 47-66; 2014: 33-51), Gómez-Ferrer (2010: 109-114) y Ferrer-Ferrer (2014: 265-271). A ello hay que sumar el interesante trabajo de Yolanda Gil Saura (2010: 5-40).

2 Corregimos, de esta manera, lo expresado en el catálogo de 2003 en el que dábamos 1692 como fecha aproximada de su ejecución (Ferrer, 2003a: 6768). Dato que coincide, sin embargo, con la realización del «cobertís» (o pasadizo) que une el castillo con la iglesia por el maestro de obras Rafael Martí y el arquitecto Gil Torralba y, por lo tanto, con la exornación esgrafiada de esta fase constructiva tardía.

3 Debemos a Josep Lluís Cebrián y Beatriu Navarro la noticia de los esgrafiados en algunos de sus paramentos, así como el aparato gráfico que nos ha permitido estudiarlos. Sobre este templo tan peculiar se ocuparon en su día Benito-Bérchez (1983: t. I, 135-144), sin aludir expresamente a esta decoración sino como «(...) abultada plástica de putti y formas vegetales escaroladas, característica del barroco valenciano más desaforado» (p. 143). Nada dice, en cambio, Garín Ortiz de Taranco (1983: t. I, 103-105, y 1986: 584-587).

4 Agradezco sobremanera a José E. Alberola Serena la noticia y las fotografías de los esgrafiados de la parroquia de la Encarnación de Nuestra Señora de esta localidad de la Vall d'Albaida, como también que me proporcionara un texto mecanografiado inédito del cura párroco Vicente García Morant (1972).

5 Agradezco a Josep A. Gisbert Santonja sus informaciones al respecto. Sobre la iglesia, puede verse: http://www.manuserran.com/index.php?option=com_content\&view=article\&id=1144:santa\&catid=238\&ltemid=465 (fecha de consulta: 10-10-2016).

\section{Bibliografía}

BENITO DOMÉNECH, Fernando y BÉRCHEZ, Joaquín (1983), «Andilla. Iglesia de la Asunción», en BÉRCHEZ, Joaquín (coord.), Catálogo de Monumentos y Conjuntos de la Comunidad Valenciana, tomo I, Generalitat Valenciana, Valencia.

FERRER ORTS, Albert (2003a), L'esplendor de la decoració esgrafiada valenciana (1642-1710) i la seua presència en l'arquitectura religiosa de Xirivella, Premi Ramon Muntaner, n. ${ }^{\circ}$ 6, Ajuntament de Xirivella, Xirivella.

- (2003b), «L'esgrafiat sis-centista en les cartoixes valencianes. Dades per a la reflexió», Archivo de Arte Valenciano, n. 84, pp. 47-54.

- (2004), La cartoixa d’Ara Christi (1585-1660), tomo I, Analecta Cartusiana, n. ${ }^{197}$, Universidad de Salzburgo, Salzburgo.

- (2005), «Apreciaciones sobre el esgrafiado valenciano», Boletín de la Sociedad Castellonense de Cultura, n. 81, pp. 967-977. 
FERRER ORTS, Albert (2009), «Els esgrafiats sis-centistes de Vilafranca», Festes patronals en honor a Sant Roc, Ajuntament de Vilafranca, Vilafranca, pp. 173-178.

- (2010), «El esgrafiado arquitectónico valenciano y su irradiación a Cataluña y Aragón», Butlletí de la Reial Acadèmia de Belles Arts de Sant Jordi, n. ${ }^{\circ} 23-24$, pp. 227-232.

-(2011), «La pell tatuada: els esgrafiats en l'arquitectura barroca de la sotsgovernació de Xàtiva», en NAVARRO i BUENAVENTURA, Beatriu (ed.), Art i historia a Xàtiva i les comarques centrals, Actes de les III Jornades d'Art, Ed. Ulleye, Xàtiva, pp. 47-66.

- (2014), «La ornamentación clásica en la creación artística: el grutesco en España», Argos, vol. 31, n. 60-61, pp. 33-51.

FERRER ORTS, Albert y FERRER DEL RíO, Estefania (2014), "Ocultar y engalanar: el esgrafiado en la arquitectura seiscentista valenciana», en BENITO GOERLICH, Daniel (ed.), La piel de los edificios, Quaderns, n. ${ }^{\text {4 }}$, Universitat de València, Valencia, pp. $265-271$.

GARCÍA MORANT, Vicente (1972), Historia de la parroquia de Beniatjar (Valencia), inédito.

GARÍN Y ORTIZ DE TARANCO, Felipe M. ${ }^{a}$ (dir.) (1983), Inventario artístico de Valencia y su provincia, tomo I, Ministerio de Cultura, Madrid. GARÍN Y ORTIZ DE TARANCO, Felipe M. ${ }^{a}$ et al. (1986), Catálogo monumental de la provincia de Valencia, Caja de Ahorros de Valencia, Valencia.

GIL SAURA, Yolanda (2004), Arquitectura Barroca en Castellón, Diputació de Castelló, Castellón.

- (2010), "Muestras, cortados y trepas. Algunas noticias sobre los esgrafiados valencianos», Lexicon. Storie e architettura in Sicilia en el Mediterraneo, n. ${ }^{\circ} 10-11$, pp. 5-40.

GÓMEZ LOZANO, Josep-Marí y FERRER ORTS, Albert (2010), «Els esgrafiats de la cartoixa de Valldecrist», Ars Longa, n. 19 , pp. $109-114$. RUIZ ALONSO, Rafael (2014a), «Cuestiones de terminología en torno al procedimiento artístico del esgrafiado y sus variantes técnicas», De Arte. Revista de Arte, n. ${ }^{\circ} 14$, pp. 22-37.

- (2014b), «Aspectos del esgrafiado en el Renacimiento español», Goya, n. ${ }^{3}$ 348, pp. 208-229.

SENA, Laura (2016), «Un palacio en todo su esplendor», Levante-EMV, 2.X, p. 45. 
